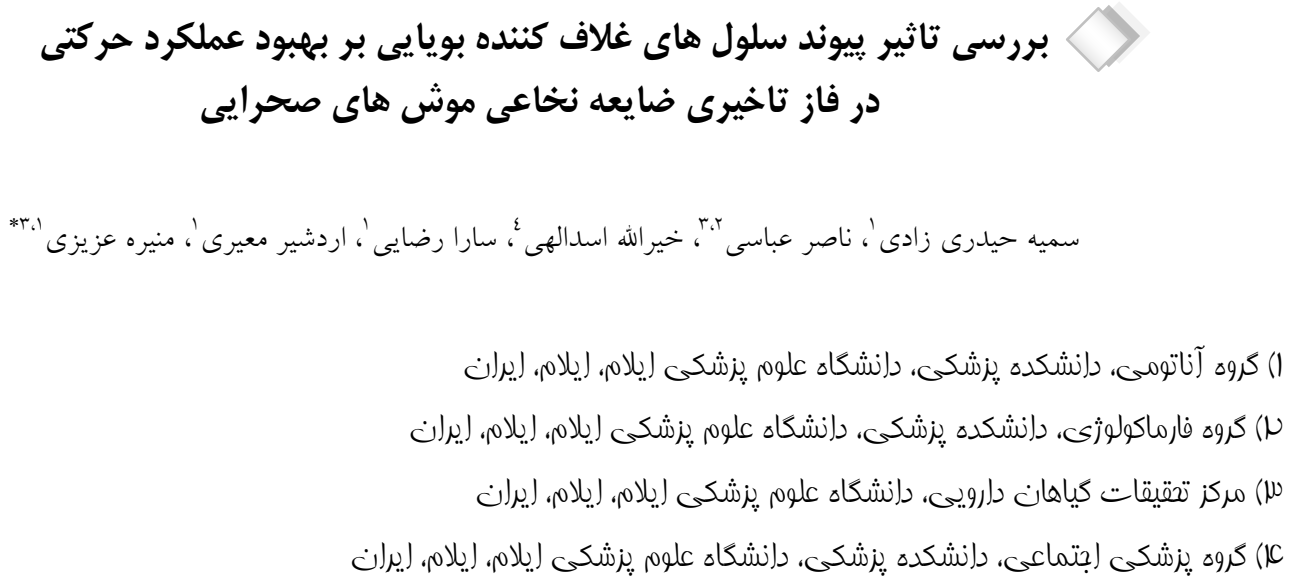

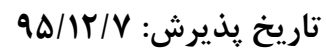

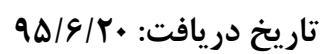

مقدمه: ضايعه نخاعى منجر به نقص هاى عملكردى غير قابل بازگشت در بيماران مى شود. ييش آَّهى بد اين ضايعه انكيزه تحقيق جهت

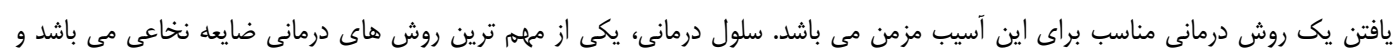

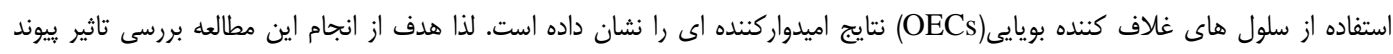

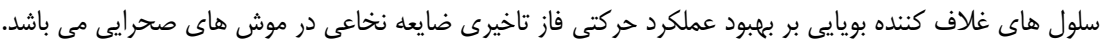

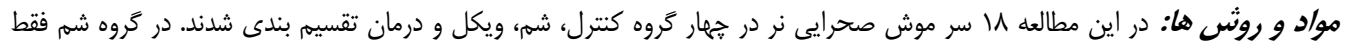

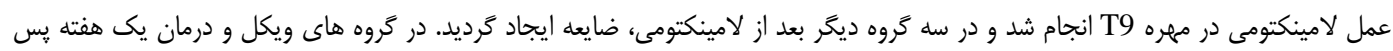

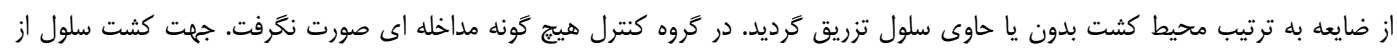

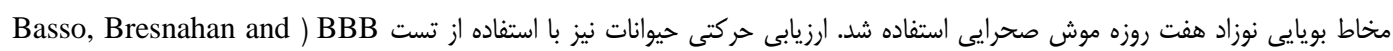
(Beattie

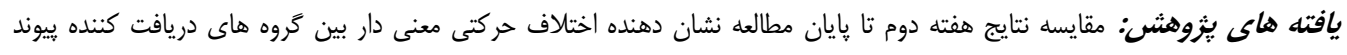

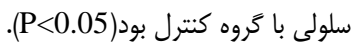

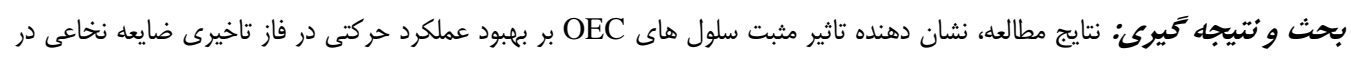
موش هاى صحر ايى مى باشد.
\end{abstract} وازه هاى كليدى: ضايعه نخاعى، سلول هاى غلاف كننده بويايى، فاز تاخيرى، عملكرد حر كتى * نويسنده مسئول: گروه آناتومى، دانشكده بزشكى، دانشخاه علوم يزشكى ايلام، ايلام، ايران-مركز تحقيقات گياهان دارويى، دانشخاه علوم بزشكى Email:azizi.moaz@gmail.com

Copyright (C) 2018 Journal of Ilam University of Medical Science. This is an open-access article distributed under the terms of the Creative Commons Attribution international 4.0 International License (https://creativecommons.org/licenses/by-nc/4.0/) which permits copy and redistribute the material, in any medium or format, provided the original work is properly cited. 
(in-vitro) VEGF, NGF, BDNF, GDNF

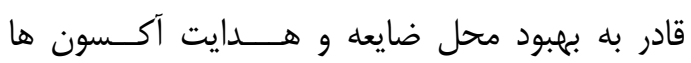

هستند(·). (1).

سلول هاى OEC نه تنها باعث ارتقاء رشد مجدد

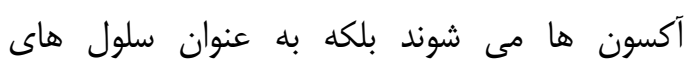

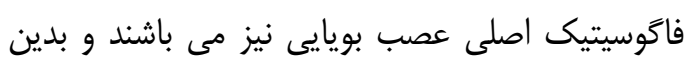

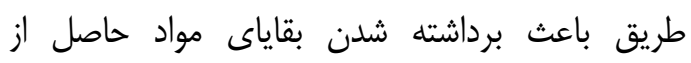

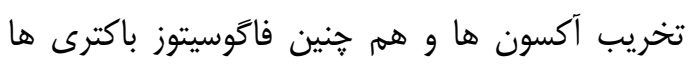
مى كردند. يّ از كاشت سلول هاى OEC

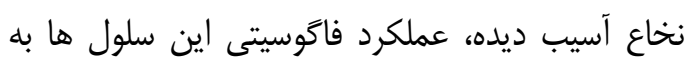
سرعت باعث حذف بقاياى سلولى و در نتيجه تعديل

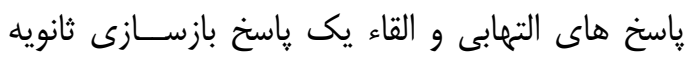

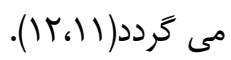

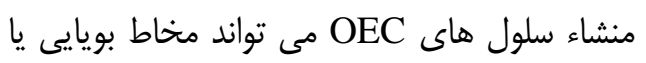

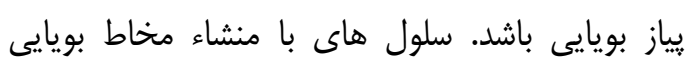

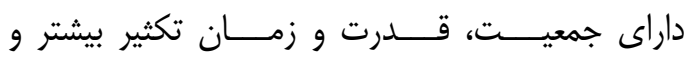

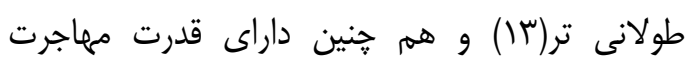

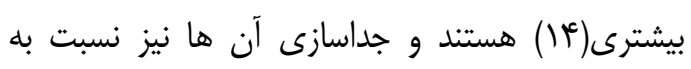

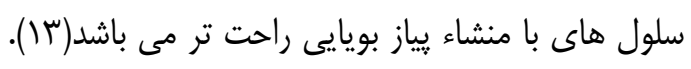

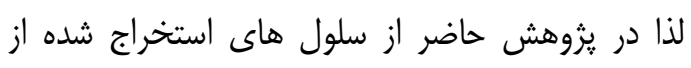

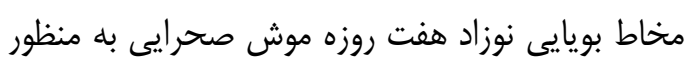

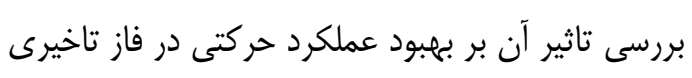
مدل كوفتگى ضايعه نخاعى استفاده كرديد.

\section{مواد و روش ها كان}

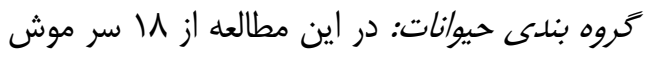

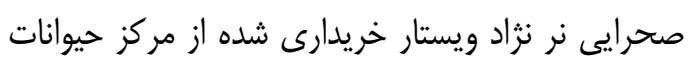

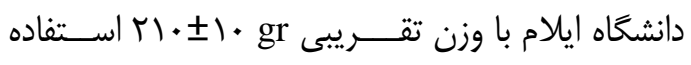

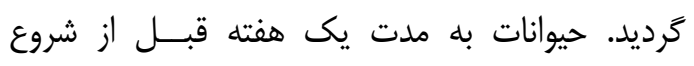

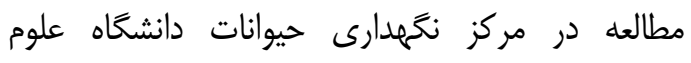

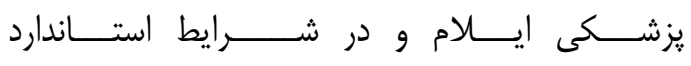

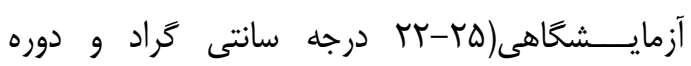

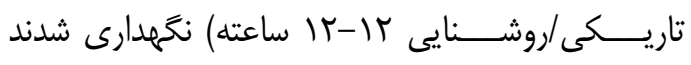

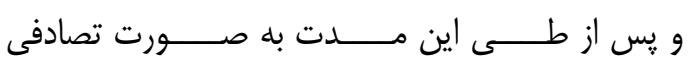

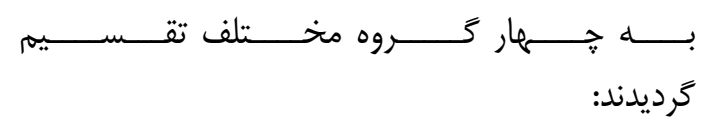

ضايعه نخاعى(SCI) يك مشكل كلينيكى جدى

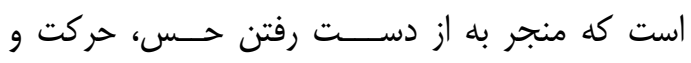

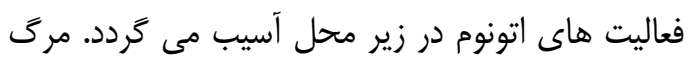

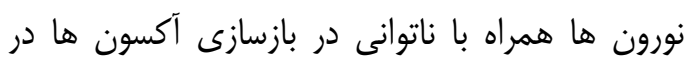
طول محل ضايعله منجر به نقص هاى دائم و غير قابل

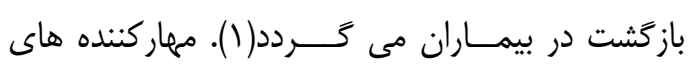

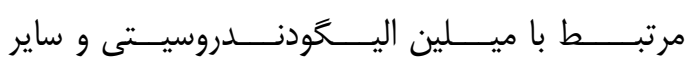
يروتئوكليكان ها، فقدان منابع نوروتروفيك مورد نياز و تشكيل اسكار كليال فاكتورهاى اصلى بازدارنده فئل رشدان

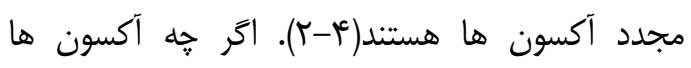

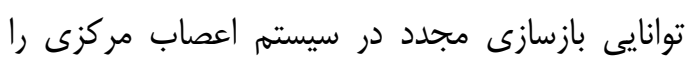

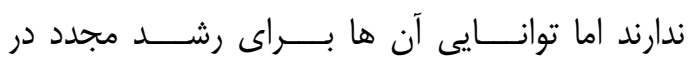

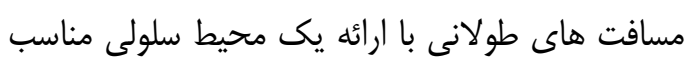
حفظ مى گردد (1). كوفتكى شايع ترين مدل ضايعه كلينيكى در انسان

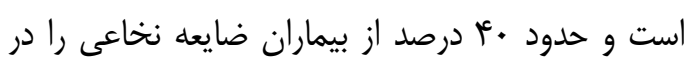

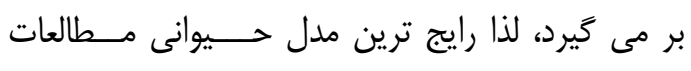

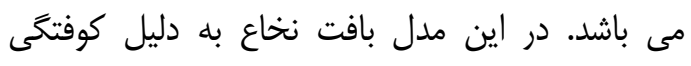

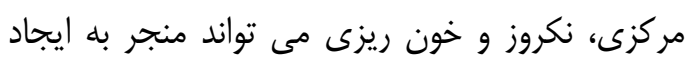

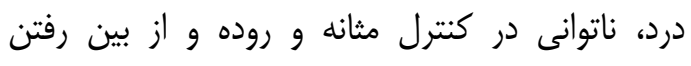

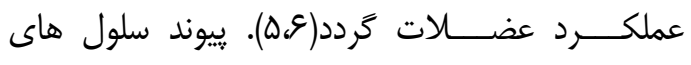
غلاف كننده بويايى درمان تجربى اميدوار كننده اى را رال

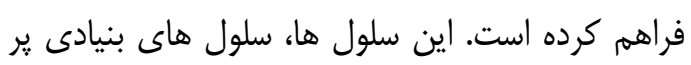

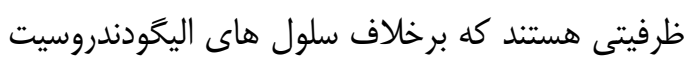

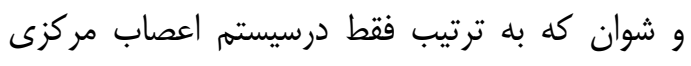
و و محيطى(CNS)

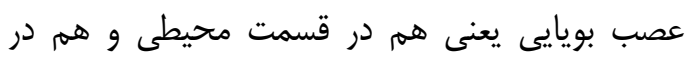

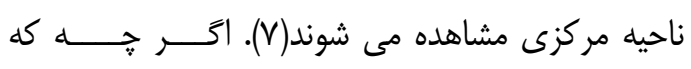

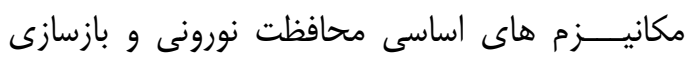
مجدد آكسون ها توسط اين سلول ها به مانه طور كامل نورون

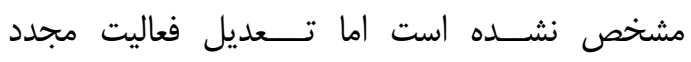
آستروسيت ها، كاهش بيان يروتئوكليكان ها، افزايش تشكيل عروق خونى جديد، بازسازى مجدد آكسون ها و ونان

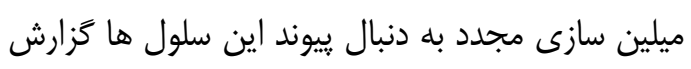

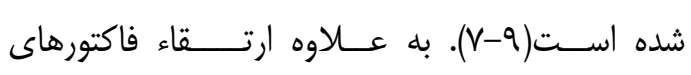
نوروتروفيك توسط اين سلول ها در مطالعات برون تنى أوه أنى 
ه م درصد و أنتى بيوتيك ا درصد و فاكتور

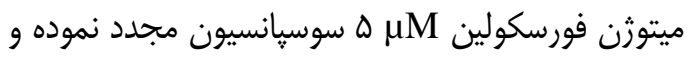

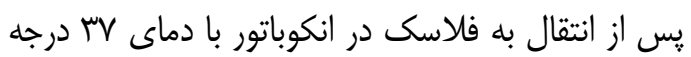

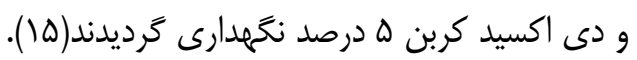
جهت حذف فيبروبلاست هاى محيط كشت از از

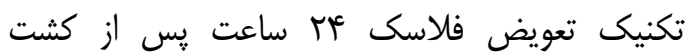

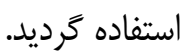

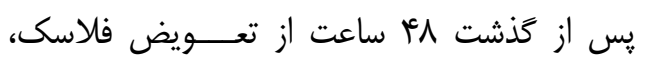
سلول ها كم كم شروع به هـبيدن به كف فلاسك با لـا

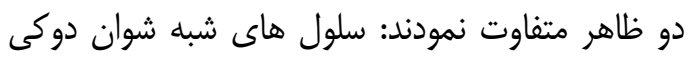

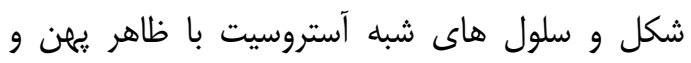

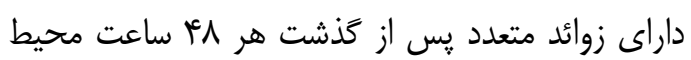
كشت فلاسك ها تعويض مى خرديد.

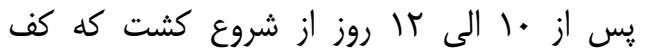

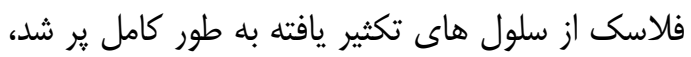
ياساز سلولى انجام مى شد.

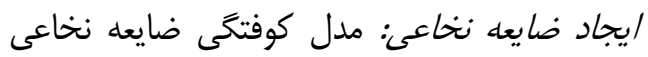
بر اساس مطالعات و به روش زير در حيوانات ايجاد كرديد:

يس از بيهوش نمودن حيوان با استفاده از مخلوط

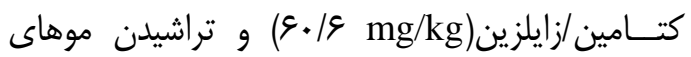
يشت حيوان و ضدعفونى نمودن محل، يك برش در

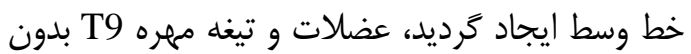

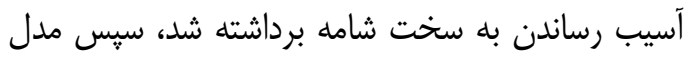

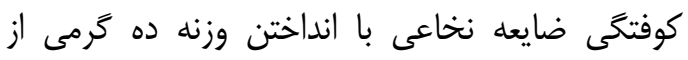
ارتفاع To mm بر روى قطعه T10 نخـــاع ايجاد

$$
\text { كرديد(ع) اعنفاع (1). }
$$

يس از ايجاد ضايعه عضلات و يوست محل بخيه كرديد، به منظور جلوكيرى از دهيدره شدن حئ حيوان

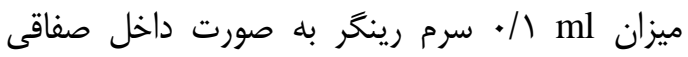
تزريق كرديد. هم جنين سفازولين(

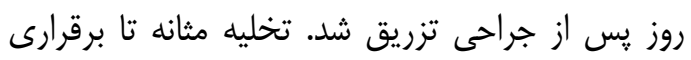
رفلكس ادرارى روزانه دوبار انجام شد.

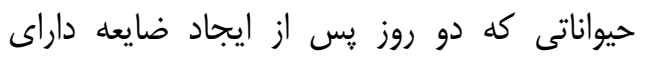
تست BBB با نمره بالاتر از سه بودند از مطالعه حذف دوالي
1-كروه كنترل(N=6): در اين گروه مدل كوفتكى ضايعه نخاعى ايجاد شد اما هيج گَونه اقدام درمانى صورت نكرفت.

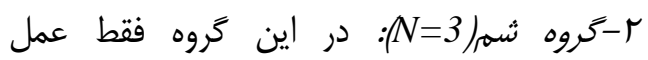
برداشتن تيغه مهره اى بدون آسيب رساندن به نخاع

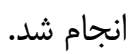

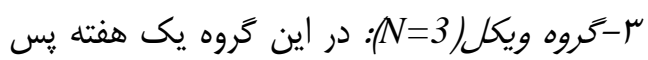

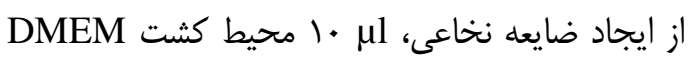

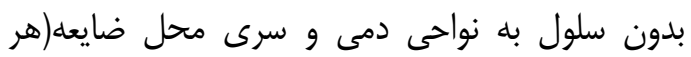

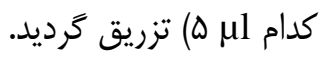

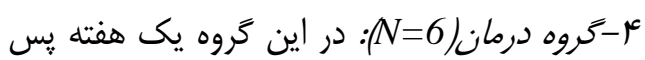

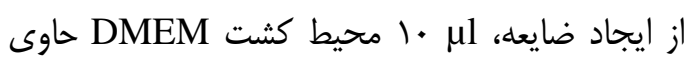

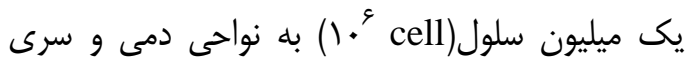
محل ضايعه(هر كدام بر ه) تزريق گرديد. لازم به ذكر است كه تمامى تزريقات در گروه هاى

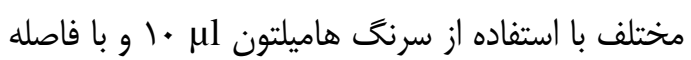

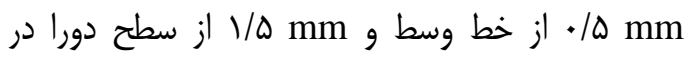
نواحى دمى و سرى ضايعه انجام شد.

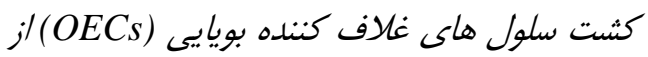

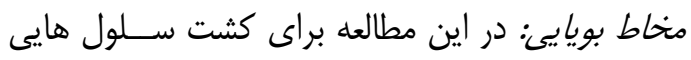

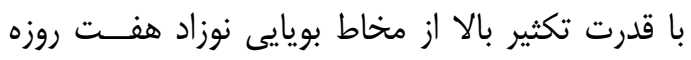

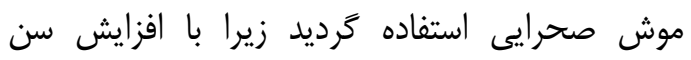

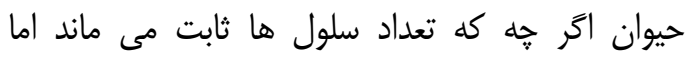

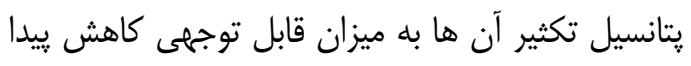

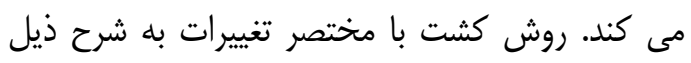

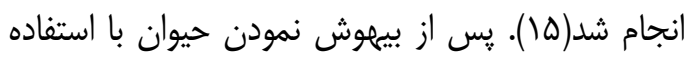

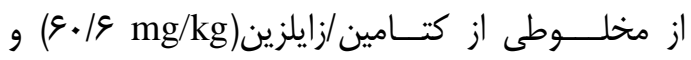

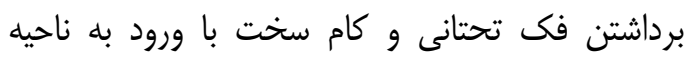

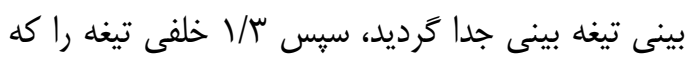

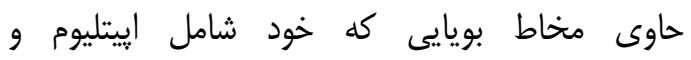
لامينايرويرياى بويايى است را جدا نموده و يس إز خرد خرد

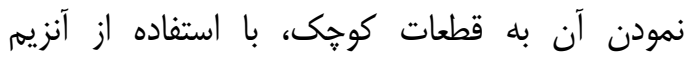

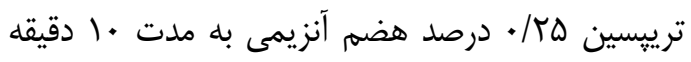

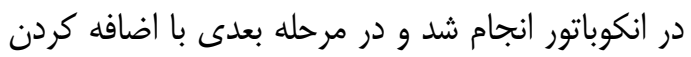
سرم جنين كاوى(FBS) فعاليت آنزيم متوقف كرديد.

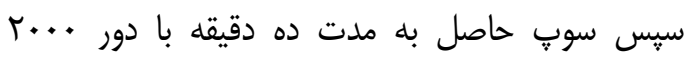

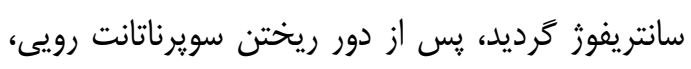

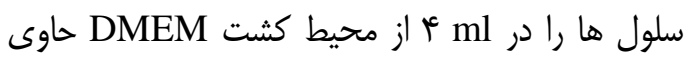


ظاهر متفاوت را نشان دادند: سلول هاى شبه شوان دوكى شكل و سلول هاى شبه آستروسيت كه داراى ظاهر يهن و زوائد متعدد بودند(شكل شماره ()).

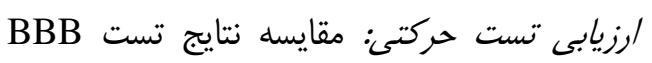

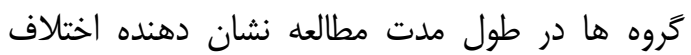
معنى دار تروه شم با ساير تروه هاى داراى ضائه

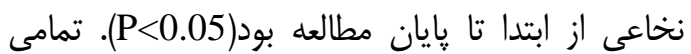

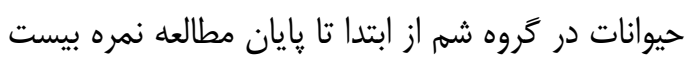

$$
\text { و يك را احراز كردند(شكل شماره r). }
$$

هم جنين در مقايسه تست حركتى گروه دريافت

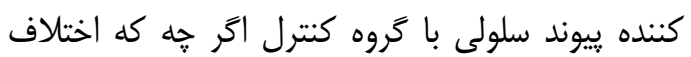
نمره آن ها در هفته اول مطالعه بى معنى بود(P>0.05)

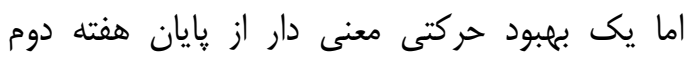

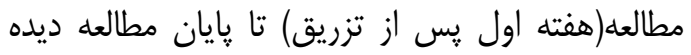

$$
\text { شد) (P=0.006). }
$$

هم حنين مقايسه نتايج هفته هاى دوم تا هشته

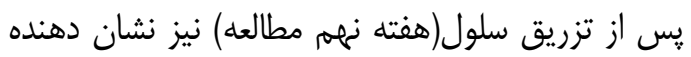

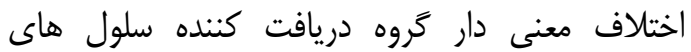

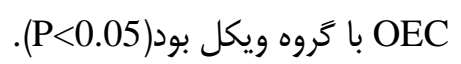

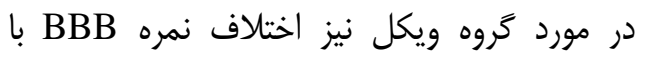

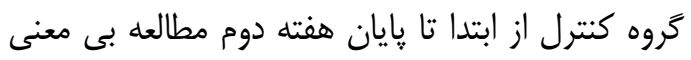

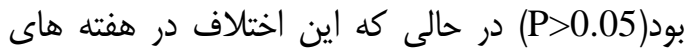

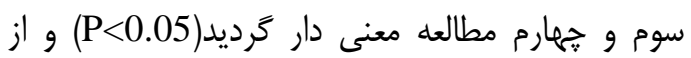

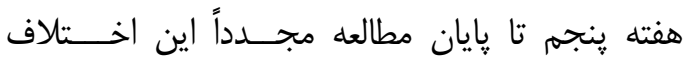
معنى دار نبود(P>0.05)(شكل شماره ؟).
ارزيابى عملكردى توسط تست حركتى BBB: به

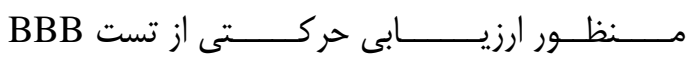

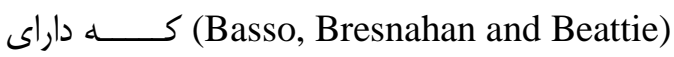
نمره هاى صفر تا بيست و يك مى باشد استفاده گرديد،

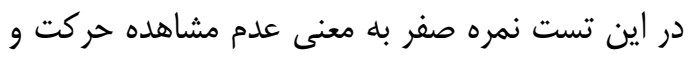

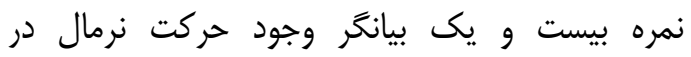
حيوانات مى باشد(IV) (IV). به اين صورت كه ارزيابى ميزان حركت در درات تمام

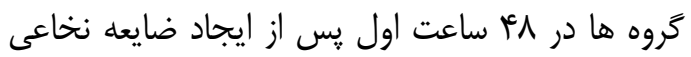

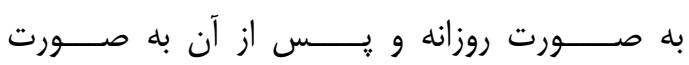

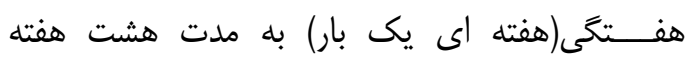

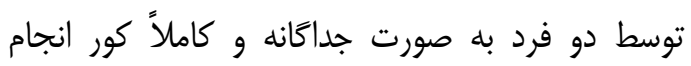

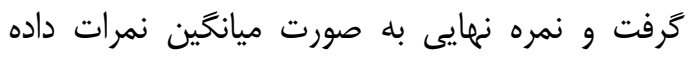

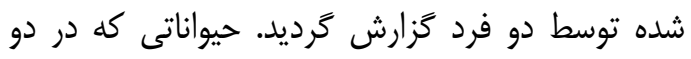
روز اول پِ از ضايعه داراى نمره حركتى سّ و بالاتر از

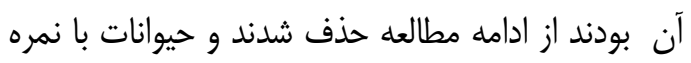
كمتر از بّ جهت ادامه مطالعه انتخاب شداند.

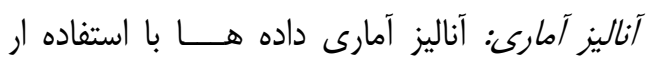

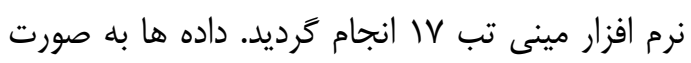
ميانخين +انحراف معيار در سطح معنى دارى(

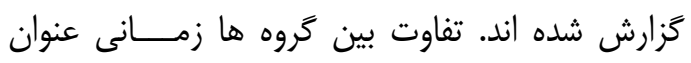

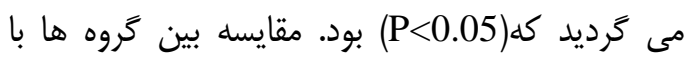
روش one-way ANOVA انجام شد.

يافته هاى يزوهش

كشت سلولى: سلول ها در كشت سلولى يس إز هئ

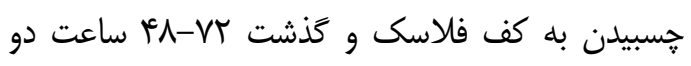

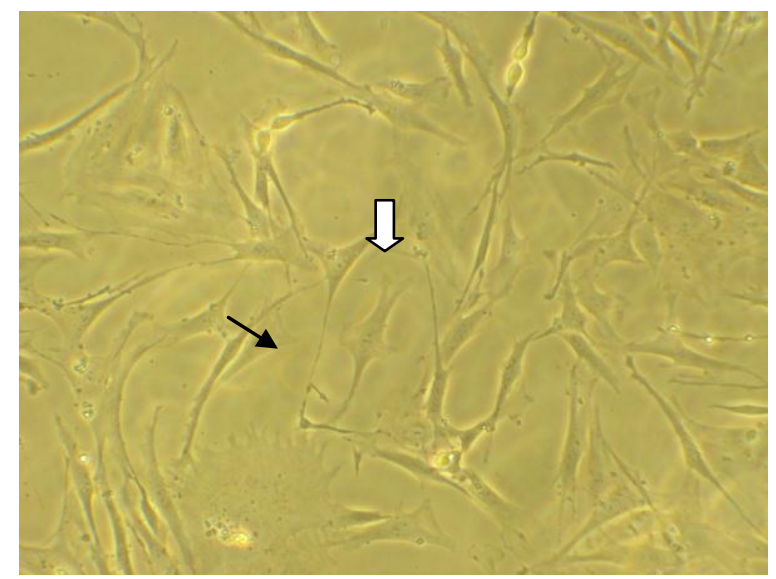

شكل شماره ا. شكل سلول هاى OEC هفت روز يّ از كشت. در كثت سلول هاى OEC فلاسك دو فنوتايب متفاوت را نشان مى دادند: سلول هاى شبه شوان دوكى شكل(فلش سياه نازك) و سلول هاى 
شبه آستروسيت كه داراى ظاهر يجهن با زوائد متعدد است(فلش سفيد).

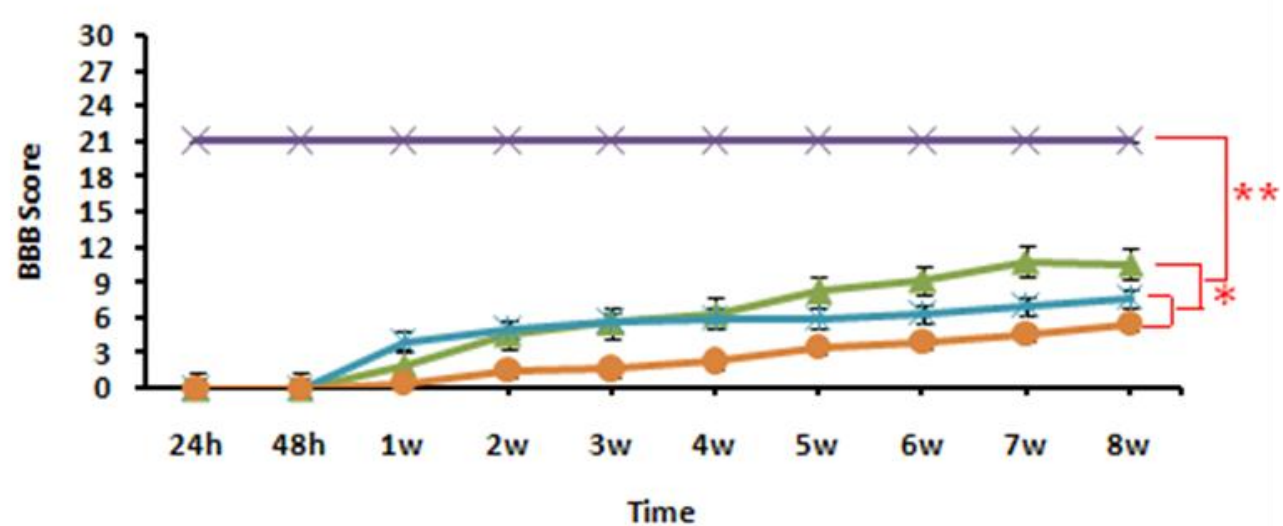

$\longrightarrow$-7days after $\mathrm{SCl} \leftarrow$ sham $\nrightarrow$ vehichel $\multimap$ control

شكل شماره r. نمودار خطى تست حركتى BBB كروه هاى مختلف از ابتدا تا پايان هفته هشتم مطالعه. نتايج به صورت

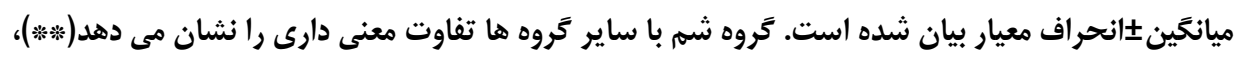

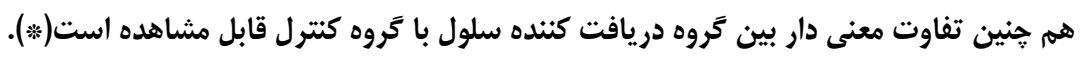

مطالعه احتمالاً ناشى از شدت ضايعه و هم جنين زمان

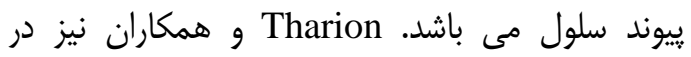

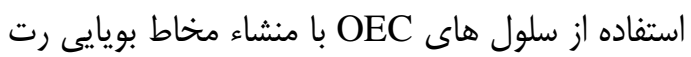
بالغ جهت درمان مدل كوفتخى ضايعه نخاعى تفاوت

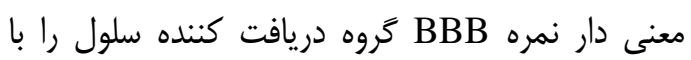

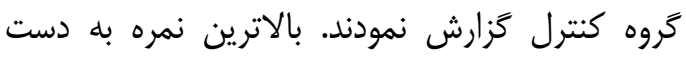

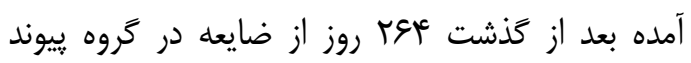

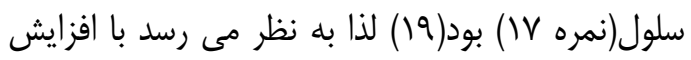
طول مدت مطالعه بتوان به نتايج مطلوب ترى دست يافت. در مقابل در مطالعه Takami و همكاران كه از

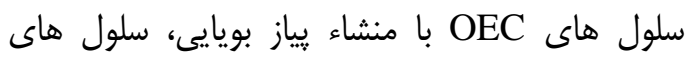

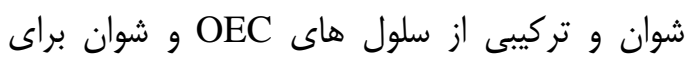

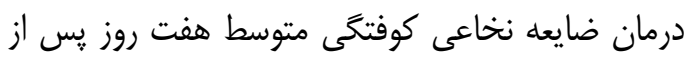

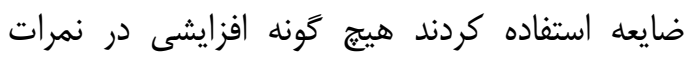
BBB

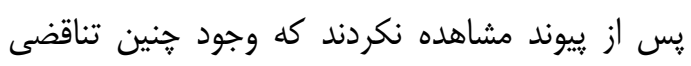
احتمالاً به دليل تفاوت در منشاء سلول هاى استفاده

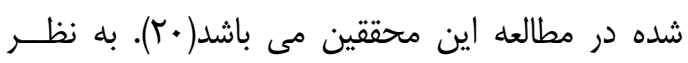
مى رسد كه نتايج كسب شده بهتر در مطالعه ما استفاده

\section{بحث و نتيجه تَيرى}

نتايج مطالعه حاضر نشـان مئس دهى دهد كه بيوند

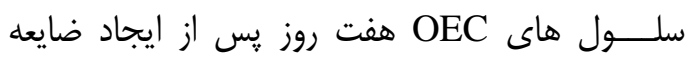

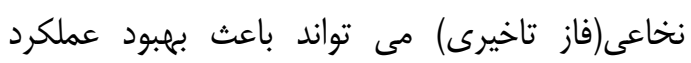

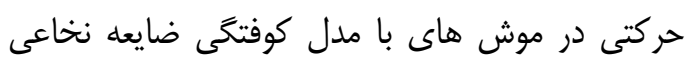
شود. در مطالعه اى كه از سلول هاى OEC و قطعات لامينايرويرياى بويايى رت بالغ در درمان قطع كامل

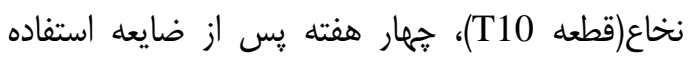

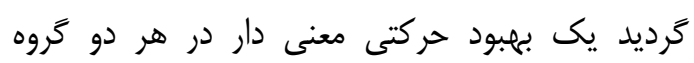
دريافت كننده ييوند سلول و قطعات لامينايرويريا از

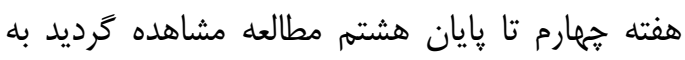

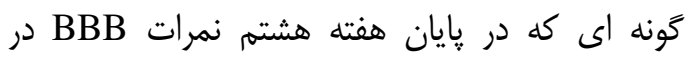
كروه هاى كنترل و دريافت كننده سلول و لامينايرويريا

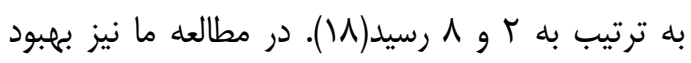

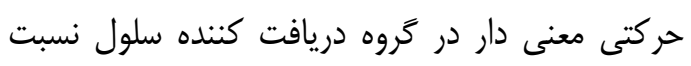

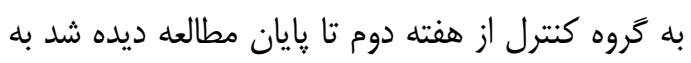
طورى كه ميانكَين نمرات BBB در يايان هفته هشتم

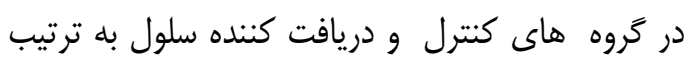

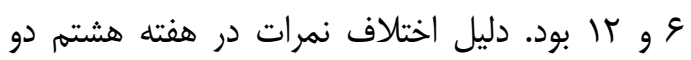


بر بهبود عملكرد حركتى در فاز تاخيرى ضايعه نخاعى

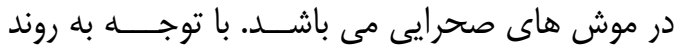
صعودى نمودار حركتى به نظر مى رسد كه با افزايش

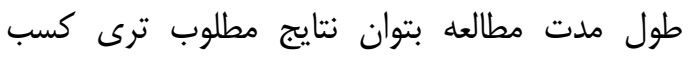

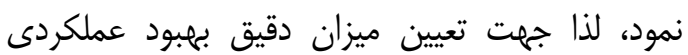
افزايش طول مدت مطالعه ييشنهاد مى گردد. سباسگَزارى

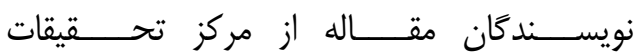

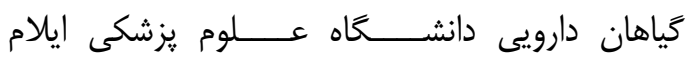

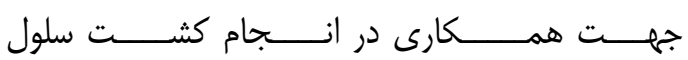

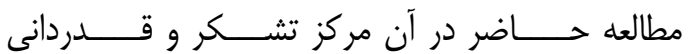
مى نمايند.

\section{References}

1. Lopezvales R, Fores J, Verdu E. Acute and delayed transplantation of olfactory ensheathing cells promote partial recovery after complete transection of the spinal cord. Neurobiol Dis2006; 21: 57-68.

2. Widenfalk J, Lundstromer K, Jubran M, Brene S, Olson L. Neurotrophic factors and receptors in the immature and adult spinal cord after mechanical injury or Kainic acid. Neuroscience 2001;21:3457-75.

3. Woolf CJ, Salter MW. Neuronal plasticity increasing the gain in pain. Science 2000;288:1765-69.

4. De Winter F, Oudega M, Lankhorst AJ, Hamers FP, Blits B, Ruitenberg MJ, et al. Injury include class 3 semaphorin expression in the rat spinal cord. Exp Neurol2002; 175:61-75.

5. Hulsebosch C. Recent advances in pathophysiology and treatment of spinal cord injury. Adv in Physiol Edu2002; 26: 238-55.

6 . Young W. Spinal cord contusion models. Prog Brain Res 2002; 137: 231-55.

7. Mayeur A, Duclos C, Honore A, Gauberti M, Drouot L, Claude J, et al. Potential of olfactory ensheathing cells from different sources for spinal cord repair. Plosone 2013; 8:62860.

8. Li Y, Field PM, Raisman G. Regeneration of adult rat corticospinal axons induced by transplanted olfactory ensheathing cells. Neuroscience 1998; 18: 10514-24.

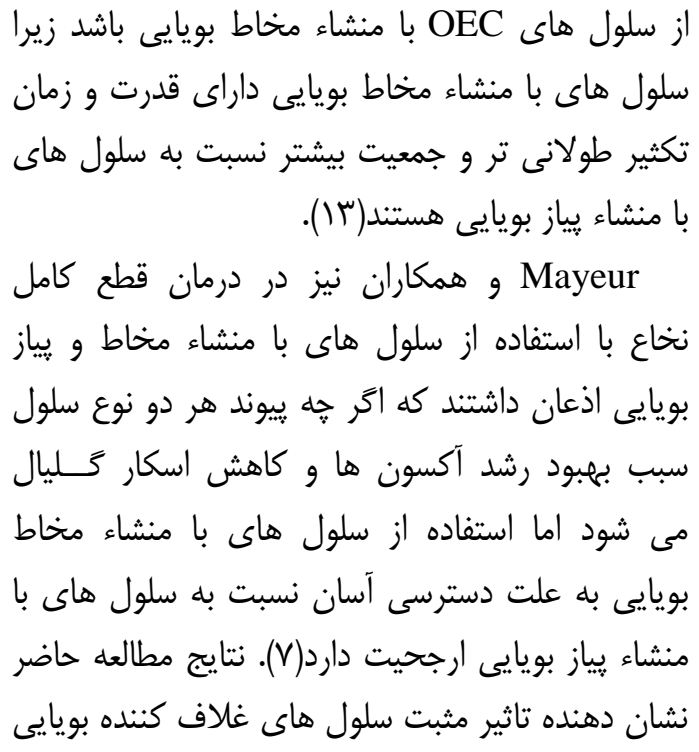

9. Li Y, Field PM, Raisman G. Repair of adult rat corticospinal tract by transplant of olfactory ensheathing cells. Science1997; 277:2000-2.

10. Woodhall E, West AK, Chuah MI. Culture olfactory ensheathing cells express nerve growth factor, brain derived neurotrophic factor, glial cell line-derived neurotrophic factor and their receptors. Brain Res 2001; 88:203-13.

11. Nazareh L, Lineburg KE, Chua MI, Tellovelasques J, Chehrehasa F, St John JA, et al. Olfactory ensheathing cell are the main phagocytic cell that remove axon debris during early development of the olfactory system. J Comp Neurol2015; 523:479-94.

12. Panni P, Ferguson IA, Beachuam I, Mackysim A, Ekberg JA, St John JA. Phagocytosis of bacteria by olfactory ensheathing cells and Schwann cells. NeuroSci Lett 2013; 539: 65-70.

13. Lu J, FeronF, Ho SM, Mackay-Sim A, Waite PM. Transplantation of nasal olfactory tissue promotes partial recovery in paraplegic adult rats. Brain Res2001;889:344-57.

14. Richter MW, Fletcher PA, Liu J, Tetzlaff W, Roskams AJ. Lamina propria and olfactory bulb ensheathing cells exhibit differential integration and migration and promote differential axon sprouting in the lesioned spinal cord. Neuroscience2005; 25:10700-11. 
15. Azizi M, Bakhtiari M, Farahmandghavi F, Zandi M, Imani M, Joghataei MT. Purity determining of cultured OECs from olfactory mucosa of Rats pups. J Bas Res Med Sci 2016; 3:12-21.

16. Heidarizadi S, Abbasi N, Asadollahi K, Rezaei S, Moayeri A, Azizi M. Effect of olfactory ensheathing cells transplantation on functional recovery in acute phase of spinal contused rats. J Bas Res Med Sci 2017; 4:30-6.

17. Basso DM, Beattie MS, Bresnahan JC. Grade histological and locomotor outcomes after spinal cord contusion using the NYU weight-drop device versus transection. Exp Neurol 1996; 139:244-56.
18. Lu J, Feron F, Makhy-Sim A, Waite PM. Olfactory ensheathing cell promote locomotor recovery after delayed transplantation into transected spinal cord. Brain2002; 125:14-21.

19.Tharion G, Indirani K, Durai M, Meenakshi M, Devasahariam SR, Prehav NR, et al. Motor recovery following olfactory ensheathing cell transplantation in rats with spinal cord injury. Neurol Ind2011; 59:566-72.

20. Takami T, Oudega M, Bates ML. Schwann cell but not olfactory ensheathing glia transplants improve hind limb locomotor performance in the moderator contused adult rat thoracic spinal cord. Neuroscience2002; 22: 6670-81. 


\title{
Effects of Olfactory Ensheathed Cells Transplantation on Functional Recovery in Delayed Phase of Spinal cord in Injured Rats
}

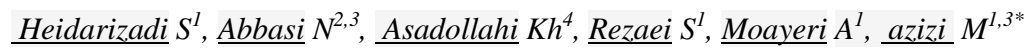

(Received: September 10, 2016

Accepted: February 25, 2017)

\begin{abstract}
Introduction: Spinal cord injury (SCI) causes constant irreversible functional deficits. Poor prognosis of such a disease prompts scientists to work on an effective way of treatment. Stem cell transplantation provides a promising strategy for such researchers .Using olfactory ensheathed cells (OECs) has, so far, indicated very good results. Hensce, the purpose of this study was to evaluate the effectiveness of transplanted OECs on functional recovery of delayed phase of SCI in rats.
\end{abstract}

Materials \& Methods: In this survey, eighteen adult male wistar rats were divided into sham, control, vehicle, and treatment groups. Sham group received only laminectomy in the T9 segment of spinal cord, while in other groups, contusion model was induced following laminectomy.7 days after injury, DMEM medium alone or with OECs was injected to the vehicle and treatment groups, respectively. For cell culture, the olfactory mucosa of 7-day-old male wistar rats was used. Locomotor behavior of animals in all the groups was evaluated by BBB, )Basso, Bresnahan and Beattie) test.

Findings: Comparison of the results by the second week to the end of the study illustrated significant changing differences between the OECs receivers and the control group, $(\mathrm{p}<0.05)$.

Discussion \& Conclusion: Our investigation demonstrated a positive impact of the OECs on functional recovery in the delayed phase of SCI.

Keywords: spinal cord injury, olfactory ensheathed cells, delayed phase, functional recovery

1. Dept of Anatomy, Faculty of Medicine, Ilam University of Medical Sciences, Ilam, Iran

2. Dept of Pharmacology, Faculty of Medicine, Ilam University of Medical Sciences, Ilam, Iran

3. Medicinal Herbs Research Center, Faculty of Medicine, Ilam University of Medical Sciences, Ilam, Iran

4. Dept of Social Medicine Group, Faculty of Medicine, Ilam University of Medical Sciences, Ilam, Iran

*Corresponding author Email:azizi.moaz@gmail.com 